\title{
18 | Genetic engineering in Aotearoa, New Zealand: a case of opening up or closing down debate? 1
}

\author{
AUDLEY GENUS AND TEE ROGERS-HAYDEN
}

\section{Introduction}

As in many countries, genetic engineering (GE) has been an issue of controversy in New Zealand. The Royal Commission on Genetic Modification (RCGM) (May 2000 to July 2001) was established as a forum for both public and expert debate, largely in response to demands from environmentalists around the 1999 election (Rogers-Hayden and Hindmarsh 2002). It provides an ideal case study for this part of the book, as the RCGM initially appeared 'open', but on closer inspection can be seen to have been 'closed' owing to significantly unquestioned assumptions shaping the whole process of inquiry, argument and deliberation. It is also of interest for the way in which the debate has gained new momentum since the RCGM, and for what it has to contribute to contemporary thinking about participation in science and technology policy.

The RCGM's apparent openness was largely attributed to its warrant, which required it to investigate possible options and relevant policy changes needed regarding GE. More specifically, its warrant was 'to receive representations upon, inquire into, investigate, and report upon the following matters:

- the strategic options available to enable New Zealand to address, now and in the future, genetic modification, genetically modified organisms, and products;

- any changes considered desirable to the current legislative, regulatory, policy, or institutional arrangements for addressing, in New Zealand, genetic modification, genetically modified organisms, and products'. (RCGM 2001a)

In addition, the template that 'interested persons' (IPs) (those groups presenting cross-examinable evidence) were required to use added to the apparent openness of the participation exercise. The template included a range of aspects of GE beyond physical risks. For example: 'the key strategic issues drawing on ethical, cultural, environmental, social, and economic risks and benefits arising from the use of genetic modification, genetically modified organisms, and products' (RCGM 2001b). 
The RCGM could be seen as having created a forum to reconcile parties with diverse approaches. Opposing viewpoints were articulated. Proponents of GE expressed their desire for less regulation, suggesting that the risks were acceptable. Meanwhile, environmental groups proposed that the risks were both uncertain and incalculable. Genetic engineering is viewed by these groups as a classic case where the precautionary principle should be implemented, as it fulfils both criteria for precaution: uncertainty and potentially serious irreversible consequences (Rogers-Hayden et al. 2002). The commissioners' response, however, demonstrates the difficulties they experienced in meeting their aim to cater for and render more convergent the diverse cultural and ethical value positions and the views of 'ordinary people', partly because this constitutes a discourse of resistance to and the 'scandalizing' of GE (see Beck 1998 on the making 'real' of ecological risks).

\section{'Expert' and 'citizen' participation}

The research summarized here initially focused on the GE controversy, as framed by the RCGM, and based on the submissions made by IPs (see Rogers-Hayden 2003). An issue raised by Beck (1998), however, draws attention to the aspects of citizen involvement. It relates to what Beck (1998: 67) calls 'reflexivity of the hazard potential', in which the 'risky industry' is its own worst enemy, and actually provokes public opposition by its own modes of behaviour, not just by the risks it is generating (see also Wynne 1996). The role of social movements in relation to ecological risks is thus to scandalize the potential dangers of (in this case GE) technology. The commission's report refers to the need to develop a 'shared framework of values', emphasizing the viewpoints of 'as many New Zealanders as possible ... as much as [that] of well-resourced organisations' (RCGM 2001c: 12). Hardly surprisingly, the commission found it difficult to balance the many different viewpoints held by stakeholders and to define an agreed ethical framework within which to accommodate the submissions of various religious, ecological, Maori (indigenous peoples) and Pakeha (European descendants) groups (Rogers-Hayden and Hindmarsh 2002). The extent to which public opinion and representative advice was ignored (9,998, or 92 per cent, of the 10,861 public submissions were against GE) (RCGM 2001c), together with a tradition of non-violent direct action, could explain the nature of public protest following the publication of the RCGM report. For example, such 'scandalizing' took the form of: the destruction of a GE potato trail at Lincoln University Crop and Food Research Institute Laboratory; a pledge by 3,500 'ordinary citizens' to take direct action against GE; the occupation by anti-GE Maori of the offices of the Environmental Risk 
Management Authority (ERMA); and a three-week hunger strike by a student in Christchurch. Generally, such actions have been seen as illegitimate by biotechnology firms, research institutes and insurers, which have referred to them as 'eco-terrorism', or 'sabotage', the work of the 'far-left' and 'needless' (New Zealand Herald, July 2001 to July 2002).

The case study highlights fundamental conflicts among the various actors with respect to their different concepts of environmental risk, its analysis, the policy-making process and relationships between science, technology and nature. Part of the problem facing the commission lay in how to recognize and reconcile these 'songlines of risk' (Jasanoff 1999), owing partly to the procedures employed to obtain testimony (RogersHayden 2003). Hence, the submission template employed made discussion of interconnected factors associated with adoption of GE difficult, since answers to its questions had to 'stand alone'. This was a process that supported a reductionist approach, where answers to questions could be viewed in isolation from each other. This approach may have been suitable for proponents of GE, but it disadvantaged those, such as the environmental groups, who preferred to present their concerns about GE within a more holistic world-view. Such a perspective emphasizes the interconnectedness of elements of the ecosystem, and of nature with society, and thus contends that arguments about various aspects of GE cannot and should not be artificially separated from each other. From this kind of perspective, it can also be recognized that different citizen positions on an issue such as GM may be rooted in different, perhaps incompatible, ontological commitments, in which case it has also to be acknowledged that conflict needs profound and searching political negotiation, with identities at stake, not only expert authority premised from within one such modernist ontological position (Latour 2000; see also Chapter 1).

Rapprochement also proved difficult because certain groups (for example, proponents of GE supported by scientific experts) saw economic progress and nature as enhanced by GE, while others (environmental groups and lay activists) saw nature to be at risk from the implementation of GE. Moreover, the case study reveals limitations on citizen involvement in building a broader-based understanding of risk connected with different perspectives on governance (see Genus 2000, 2003). These have ranged from reliance on subordination of the citizenry to state and expert authority (the government, scientists, industrialists), through (claimed) equality of people, while subordinating nature (RCGM) to holistic approaches emphasizing the equality of people and nature (environmental campaigners; see Dryzek 1997). 